\title{
DA INSEGURANÇA JURÍDICA À PRECARIZAÇÃO DAS RELAÇÕES DE EMPREGO: OS IMPACTOS DA REFORMA TRABALHISTA NO BRASIL
}

\section{Suzéte da Silva Reis ${ }^{1}$}

\section{RESUMO}

A edição da Lei n. 13.467, que promoveu a reforma trabalhista, provocou inquietações e gerou dúvidas e, apesar de já se encontrar em vigor no ordenamento jurídico, continua sendo objeto de variadas interpretações e de inúmeras ações judiciais, inclusive questionando a sua constitucionalidade, eis que contraria expressamente dispositivos constitucionais. Diante disso, a problemática que norteou a realização do presente trabalho é: quais os impactos promovidos pela reforma trabalhista? Para realização deste trabalho, que tem como objetivo analisar as principais alterações promovidas pela reforma trabalhista e seus impactos, adotouse o método hipotético-dedutivo e foi empregada a técnica de pesquisa bibliográfica.

Palavras-chave: Insegurança jurídica. Precarização do trabalho. Reforma trabalhista.

\section{FROM LEGAL UNCERTAINTY TO JOB INSECURITY: IMPACTS OF THE LABOR REFORM IN BRAZIL}

\begin{abstract}
The enactment of Law n. 13.467, which promoted the labor reform, has provoked uneasiness and generalized uncertainty. In spite of already being in order, it is still object of several interpretations and numerous judicial actions. As it explicitly contradicts constitutional provisions, even its constitutionality was brought into question. Hence, the research question is: what are the impacts of the labor reform? In order to fulfill the aim of analyzing the main changes prompted by the labor reform and its consequences, the hypothetic-deductive method was employed, as well as a bibliographic research technique.
\end{abstract}

Keywords: Legal Uncertainty. Job Insecurity. Labor Reform.

\section{Introdução}

Em vigor desde 11 de novembro de 2017, a Lei n. 13.467, que promoveu a reforma trabalhista, causou rebuliço não apenas no âmbito das relações de trabalho, mas também no âmbito jurídico. Além da modificação de mais de uma centena de artigos da Consolidação das Leis do Trabalho (CLT), apenas três dias após a sua vigência, a mesma sofreu a primeira alteração, através da Medida Provisória n. 808, de 14 de novembro de 2017, que promoveu alterações em 85 artigos e que teve o fim de sua vigência em 23 de abril de 2018.

A insegurança e os questionamentos quanto à constitucionalidade e a possibilidade de precarização do trabalho tem sido constantes. Há controvérsias de interpretação entre

\footnotetext{
${ }^{1}$ Doutora em Direito pela Universidade de Santa Cruz do Sul - UNISC. Professora Convidada do Programa de Pós-Graduação em Direito e do Curso de Graduação em Direito da Universidade de Santa Cruz do Sul - UNISC. E-mail: sreis@ unisc.br
} 
empregadores, empregados e sindicatos. Inclusive na magistratura do trabalho observa-se que, face a complexidade e conflituosidade das alterações promovidas pela reforma trabalhista, não foram adotados posicionamentos e interpretações unânimes: enquanto alguns juízes passaram a aplicar imediatamente os novos dispositivos da CLT, outros tantos aguardam e analisam os impactos dos mesmo nas relações de trabalho.

No Superior Tribunal Federal (STF) já foram ajuizadas quase duas dezenas de ações que questionam a constitucionalidade de artigos da Lei 13.467. Até o momento, foi analisado apenas a constitucionalidade do fim da contribuição sindical obrigatória. As demais aguardam análise da corte constitucional.

Enquanto isso, temas como a dispensa coletiva, a prevalência do negociado sobre o legislado, a aplicação da sucumbência nas ações ajuizadas antes da entrada em vigor da reforma, dentre outros, têm sido objeto de ações nos diferentes Tribunais Regionais do Trabalho e as decisões têm sido nos mais diversos sentidos. Os fundamentos das decisões também repousam nas mais diferentes interpretações da legislação em vigor.

Assim, a segurança jurídica encontra-se ameaçada. A incerteza quanto aos desdobramentos gera situações atípicas, tanto entre os empregadores quanto entre os empregados.

Por outro lado, a alteração ou inclusão de alguns dispositivos na CLT provocam inquietações e geram inúmeras dúvidas. A criação de novas modalidades de contratação, como o trabalho intermitente e a possibilidade de contratação de trabalhador autônomo com subordinação e sem vínculo empregatício são exemplos que causam apreensão, pois contrariam a principiologia na qual está assentado o direito do trabalho.

Outros temas, como o teletrabalho, a demissão por comum acordo entre as partes, o termo de quitação anual das verbas trabalhistas, a possibilidade de prevalência do que for pactuado no contrato de trabalho quando o empregado possuir curso superior e receber salário igual ou superior ao dobro do limite dos benefícios da Previdência Social, a exclusão de determinadas parcelas, ainda que habituais, do cômputo da remuneração também são objeto de controvérsias e questionamentos.

Assim, diante de tantas incertezas, o presente trabalho pretende responder ao seguinte problema de pesquisa: quais os impactos promovidos pela reforma trabalhista? Tem-se, como objetivo geral, analisar as principais alterações promovidas pela reforma trabalhista e seus impactos. Para tanto, adotou-se o método hipotético-dedutivo e foi empregada a técnica de pesquisa bibliográfica. 


\section{A insegurança jurídica promovida pela reforma trabalhista}

O primeiro ponto a ser destacado diz respeito ao processo de elaboração da Lei n. 13.467, que foi aprovada num curto espaço de tempo, sem o amadurecimento do debate e a efetiva participação da sociedade. Em razão da complexidade e do número de dispositivos que foram alterados, acrescentados ou revogados na CLT, esperava-se que a discussão alcançasse uma maior abrangência. Não foi o que ocorreu.

A aprovação pelo Senado Federal, com o compromisso de veto presidencial em determinados pontos da reforma, provocou a primeira grande intervenção do governo apenas três dias após a entrada em vigor da nova Lei. A Medida Provisória n. 808, de 14 de novembro de 2017, alterou de forma significativa a reforma, alcançando cerca de 85 dos dispositivos recém reformados. No entanto, por decurso de prazo, a mesma perdeu a eficácia em 23 de abril de 2018.

Mesmo antes da entrada em vigor, a nova lei já era alvo de ações judiciais questionando sua constitucionalidade ou então a inconstitucionalidade de diversos artigos. Da mesma forma, o debate sobre os limites da negociação coletiva, que em determinadas situações poderá prevalecer sobre a própria lei, inclusive com a redução ou supressão de direitos, é também objeto de análise e de discussões.

A segurança jurídica encontra garantia no art. $5^{\circ}$, XXXVI da Constituição Federal, que dispõe que a lei não prejudicará o direito adquirido, o ato jurídico perfeito e a coisa julgada. Contudo, a aplicação da lei no tempo é um dos temas mais controvertidos do direito hodierno, porque se tem, de um lado, a segurança jurídica, e de outro, a possibilidade e necessidade de mudança (MENDES, 2013).

Para Canotilho (1993), o princípio da segurança jurídica, somado ao da confiança do cidadão, podem ser considerados como os elementos constitutivos do Estado Democrático de Direito. A segurança jurídica tem por função, portanto, assegurar proteção contra mudanças retroativas.

A dificuldade principal, no caso da reforma trabalhista, repousa na interpretação do significado de direito adquirido e a sua aplicabilidade no âmbito judicial. Ainda que o art. $6^{\circ}$ da Lei de Introdução ao Código Civil defina os conceitos de cada um dos institutos, a controvérsia permanece.

$\mathrm{O} \S 2^{\circ}$ do art. $6^{\circ}$ da referida lei dispõe que "Consideram-se adquiridos assim os direitos que o seu titular, ou alguém por ele, possa exercer, como aqueles cujo começo do exercício 
tenha termo pré-fixo, ou condição pré-estabelecida inalterável, a arbítrio de outrem (BRASIL, 2010). Algumas das mudanças estabelecidas pela reforma trabalhista esbarra justamente no conceito de direito adquirido, tomando-se como exemplo a supressão do pagamento da hora in itinere, a impossibilidade de fracionamento das férias aos trabalhadores com mais de 50 anos de idade ou a integração dos prêmios pagos de forma habitual à remuneração do trabalhador. Nessas situações, a questão é se se trata de direito adquirido ou não.

Mendes (2013, p. 370) defende que o objetivo do princípio constitucional "não se mostra apto a proteger posições jurídicas contra eventuais mudanças dos institutos jurídicos ou dos próprios estatutos jurídicos previamente fixados”. No entanto, nos exemplos supra citados, a questão afeta diretamente os direitos que já integravam o patrimônio jurídico daqueles trabalhadores e trabalhadoras e que, com a entrada em vigência da nova lei, poderão vir a ser suprimidos.

Reale (1994, p. 86), afirma que a segurança tem "algo de subjetivo, um sentimento, a atitude psicológica dos sujeitos perante o complexo de regras estabelecidas como expressão genérica e objetiva da segurança da mesma" e que o "direito de exigibilidade é razão da existência da norma positiva". Afirma também que

[...] se é verdade que quanto mais o direito se torna certo, mais gera condições de segurança, também é necessário não esquecer que a certeza estática e definitiva acabaria por destruir a formulação de novas soluções mais adequadas à vida, e essa impossibilidade de inovar acabaria gerando a revolta e a insegurança. Chego mesmo a dizer que uma segurança absolutamente certa seria uma razão de insegurança, visto ser conatural ao homem - único ente dotado de liberdade e de poder de síntese - o impulso para a mudança e a perfectibilidade, o que Camus, sob outro ângulo, denomina "espírito de revolta (REALE, 1994, p. 87).

Para Canotilho (2002), a ideia de segurança jurídica está relacionada a necessidade humana de ter alguma certeza, sem variações no decorrer do tempo, de modo que se possa organizar e coordenar a vida. Assim, o cidadão tem o direito de confiar que as decisões públicas que incidam "sobre os seus direitos, posições ou relações jurídicas alicerçadas em normas jurídicas vigentes e válidas por esses atos jurídicos deixados pelas autoridades com base nessas normas se ligam os efeitos jurídicos previstos e prescritos no ordenamento jurídico poderes" (CANOTILHO, 2002, p. 257).

A segurança jurídica está diretamente relacionada ao modelo de Estado que se pretende construir e, tanto a segurança jurídica quanto a confiança são inerentes ao Estado de Direito. Portanto, enquanto “[...] subprincípio do Estado de Direito, assume valor ímpar no 
sistema jurídico, cabendo-lhe papel diferenciado na realização da própria noção de justiça material" (MENDES, 2013, p. 372).

No mesmo sentido, Barroso (2004, p. 352) afirma que

O sistema jurídico ideal se consubstancia em uma distribuição equilibrada de regras e princípios, nos quais as regras desempenham o papel referente à segurança jurídica - previsibilidade e objetividade das condutas - e os princípios, com sua flexibilidade, dão margem à realização da justiça no caso concreto.

Compartilhando o mesmo entendimento, Perez Luño (1990) defende que a segurança jurídica se converteu num valor e num princípio informador supernormativo do ordenamento jurídico, assim como apresenta-se como componente e promotor da justiça. Para o autor, a segurança jurídica assume o papel de valor e de princípio de tripla proteção: inspiradora das relações que ocorrem na esfera pública entre Estado e os cidadãos; garantia da autonomia da vontade nas relações jurídico-privadas; e impulsora da liberdade civil nas relações público/privado.

A segurança jurídica, enquanto expressão inarredável do Estado de Direito, assume o status de subprincípio concretizador do princípio fundamental e estruturante do Estado de Direito, constituindo-se, além de princípio fundamental da ordem estatal, também um princípio fundamental da ordem jurídica internacional (SARLET, 2010).

E é nessa perspectiva que as alterações promovidas pela Lei n. 13.467 podem representar, de alguma forma, impactos na segurança jurídica, pois se configuram como retrocesso social. A proibição de retrocesso social é uma garantia constitucional e deve ser compreendida em uma acepção mais ampla, isto é, não restrita apenas a seara dos direitos sociais. Sarlet (2010) defende que a proibição de retrocesso social diz respeito à possibilidade de limitação da auto-reversibilidade das medidas do poder público que tenham assegurado direitos fundamentais, não se restringindo tão somente aos direitos sociais.

A preocupação decorrente das alterações promovidas pela Lei n. 13.467 diz respeito justamente a essas questões, porque impactam diretamente nas relações de trabalho, em determinados momentos, inclusive, contrariando os dispositivos constitucionais e os princípios que sustentam o direito do trabalho.

Um dos impactos da reforma trabalhista é a insegurança jurídica. A começar pela própria constitucionalidade da lei, que é questionada junto ao Supremo Tribunal Federal (STF). A Ação Direta de Inconstitucionalidade (ADI) 5766 foi ajuizada pelo então Procurador-geral da República, Rodrigo Janot, e questiona a constitucionalidade do artigo 790-B da CLT - caput e $\S 4^{\circ}$, que responsabiliza a parte sucumbente, ainda que beneficiária 
da gratuidade judiciária, pelo pagamento de honorários periciais e do artigo 791-A, que considera que serão devidos honorários de sucumbência por beneficiários da Justiça Gratuita. O fundamento da ação é a violação do artigo $5^{\circ}$, inciso LXXXIV da Constituição Federal que estabelece que o "Estado prestará assistência jurídica integral e gratuita aos que comprovarem insuficiência de recursos". Segundo o Procurador-Geral os dispositivos inviabilizam que o trabalhador economicamente desfavorecido assumam os riscos naturais de uma demanda trabalhista ao lhes impor o pagamento de custas e despesas processuais em caso de sucumbência, com o uso de créditos trabalhistas que por ventura venham a ser auferidos no processo. Essa ação tem como relator o Ministro Luis Roberto Barroso e ainda não foi pautada para julgamento.

Somente questionando a constitucionalidade dos artigos 454, 578, 579, 582, 587 e 602 da CLT, que tratam da contribuição sindical, foram ajuizadas 14 ações: a ADI 5794, ajuizada pela Confederação Nacional dos Trabalhadores em Transporte Aquaviário e Aéreo, na pesca e nos portos (CONTTMAF); a ADI 5806, ajuizada pela Confederação Nacional dos Trabalhadores na atividade profissional dos empregados na prestação de serviços de segurança privada, de monitoramento, ronda motorizada e de controle eletro-eletrônico e digital (CONTRASP); a ADI 5811, ajuizada pela Confederação Nacional dos Trabalhadores na movimentação de mercadores em geral e logística; a ADI 5813, ajuizada pela Federação Nacional dos empregados em postos de serviços de combustíveis e derivados de petróleo (FENOSPETRO); a ADI 5815, ajuizada pela Federação Nacional dos trabalhadores em empresas de telecomunicações e operadores de mesas telefônicas (FENATTEL); a ADI 5850, ajuizada pela Confederação Nacional dos Trabalhadores em Comunicações e Publicidade (CONTCOP); a ADI 5859, ajuizada pela Confederação Nacional do Turismo (CNTur); a ADI 5865, ajuizada pela Confederação dos Servidores Públicos do Brasil (CSPB); a ADI 5885, ajuizada pela Confederação dos Servidores e funcionários públicos das fundações, autarquias e prefeituras municipais (CSPM); a ADI 5887, ajuizada pela Federação das entidades sindicais dos oficias de justiça do Brasil (FESOJUS/BR); a ADI 5888, ajuizada pela Confederação Nacional dos Trabalhadores em Turismo e Hospitalidade (CONTRATUH), Confederação Nacional dos Trabalhadores em Transporte Terrestre (CNTTT), Confederação Nacional dos Trabalhadores na indústria (CNTI), Confederação Nacional dos Trabalhadores em estabelecimentos de ensino e cultura (CNTEEC); a ADI 5892, ajuizada pela Confederação Nacional dos Trabalhadores Metalúrgicos (CNTM); a ADI 5900, ajuizada Confederação Nacional dos Trabalhadores em Saúde (CNTS); e a ADI 5912, ajuizada pela Federação 
Nacional dos trabalhadores em serviços, asseio e conservação, limpeza urbana, ambiente e áreas verdes. Em todas, o relator é o Ministro Edson Fachin.

A ADI 5810, ajuizada pela Central das Entidades de Servidores Públicos (CESP) questiona a constitucionalidade dos artigos 545, 578, 579, 582, 587, 602 (que tratam da contribuição sindical), o inciso XXVI do artigo 611-B e a inclusão do Título IV-A - Da representação dos empregados, dos artigos 510-A ao 510-D e seus parágrafos, bem como a revogação os artigos 601 e 604 do texto anterior da CLT. O relator também é o Ministro Edson Fachin.

A ADI 5826, ajuizada pela Federação Nacional dos Empregados em Postos de Serviços de Combustíveis e Derivados de Petróleo (FENEPOSPETRO) e a ADI 5829, ajuizada pela Federação Nacional dos Trabalhadores em Empresas de Telecomunicações e Operadores de Mesas Telefônicas (FENATTEL), questiona a constitucionalidade dos artigos 443, caput e parágrafo $3^{\circ}$; 452-A, caput parágrafos; 452-B, 452-D, 452-C, 452-E, 452-F, 452G, 452-H e 911, caput e parágrafos $1^{\circ}$ e $2^{\circ}$, todos da Consolidação das Leis do Trabalho. Esses dispositivos preveem o contrato de trabalho intermitente. $\mathrm{O}$ fundamento da ação é que os dispositivos questionados violam os princípios da dignidade da pessoa humana e da isonomia, além de desrespeitarem os incisos XIII e XIV do artigo $7^{\circ}$ da Constituição Federal que tratam da jornada de trabalho e da remuneração da jornada extraordinária e por contrariar o princípio da vedação ao retrocesso social. Ambas têm como relator o Ministro Edson Fachin.

A ADI 5867 foi ajuizada pela Associação Nacional dos Magistrados da Justiça do Trabalho (ANAMATRA) e questiona o $§ 4^{\circ}$ do artigo 899 da CLT que dispõe que o depósito recursal será feito em conta vinculada ao juízo e corrigido com os mesmos índices da poupança. O relator é o Ministro Gilmar Mendes.

A ADI 5870 também foi ajuizada Associação Nacional dos Magistrados da Justiça do Trabalho (ANAMATRA) para questionar a constitucionalidade do artigo 223-G da CLT, modificado pela Medida Provisória n. 808 e que trata da tarifação do dano extrapatrimonial. $\mathrm{O}$ relator também é o Ministro Gilmar Mendes.

A Advogacia-Geral da União (AGU) enviou ao Supremo Tribunal Federal uma manifestação nos autos da ADI 5810, destacando a constitucionalidade dos artigos que preveem a extinção da contribuição sindical obrigatória, com o argumento de que é justamente a obrigatoriedade do pagamento que contradiz com o princípio da liberdade sindical, assegurado constitucionalmente. Na manifestação, a AGU ressalta que as entidades 
sindicais tiveram tempo hábil, desde a promulgação da Constituição Federal de 1988, para buscar outras fontes de financiamento, além da contribuição obrigatória e que a legislação, portanto, não representa nenhuma novidade ou ameaça a sobrevivência dos entes sindicais.

Até o momento, o Supremo Tribunal Federal julgou apenas a ADI 5794 e declarou constitucional o fim da contribuição sindical ${ }^{2}$. Dentre os argumentos dos ministros que votaram a favor está o princípio constitucional da liberdade sindical. Desse modo, prevalece, a partir de agora, o disposto no art. 578 da CLT, que exige a autorização prévia e expressa dos empregados para que o empregador efetue o desconto da contribuição sindical. As demais ações aguardam tramitação no Supremo Tribunal Federal e, dependendo da decisão, provocarão mudanças nos contratos de trabalho e causarão impactos, tanto para empregados quanto para empregadores.

Reflexo direto da insegurança jurídica é que enquanto o Supremo Tribunal Federal não analisava as ações diretas de inconstitucionalidade, vários sindicatos ingressaram em juízo pleiteando o pagamento da contribuição sindical. Algumas decisões foram favoráveis. Exemplo é a ação ajuizada pelo Sindicato dos Trabalhadores do Serviço Público Municipal de Campinas, junto ao Tribunal Regional do Trabalho da $15^{\text {a }}$ Região, na qual foi determinado recolhimento da contribuição pelo município. Dentre os fundamentos, o Juiz convocado diz que a edição da lei ordinária que fez cessar abruptamente a contribuição sindical obrigatória, que era uma das principais fontes de custeio do sindicato, abalou a segurança jurídica e a confiança do cidadão na Constituição, afetando a organização do sistema sindical, na medida em que criou empecilhos ao exercício da liberdade sindical.

$\mathrm{Na}$ ação civil pública, ajuizada pelo Sindicato dos Trabalhadores nas Indústrias de Alimentação de São Paulo na $3^{\text {a }}$ Vara de São Caetano do Sul, São Paulo, a decisão declarou inconstitucional trechos da Lei 13.467 que preveem o desconto da contribuição apenas para os empregados que autorizarem prévia e expressamente o desconto e manteve a contribuição. Um dos fundamentos foi o de que a nova legislação priorizou o interesse individual em face do coletivo e, com isso, violou princípios da Constituição Federal. Para o Juiz que julgou a ação, é o interesse da categoria que deve ser levado em consideração, e não o interesse individual de cada um dos seus integrantes. A contribuição sindical tem a finalidade de dar condições aos sindicatos para que atuem na defesa dos interesses da categoria, desse modo, contribuindo para a sociedade.

\footnotetext{
${ }^{2}$ As demais ações que tratavam do mesmo tema foram apensadas à ADI 5794.
} 
Em Santa Catarina, o Sindicato dos Empregados em Posto de Venda de Combustíveis e Derivados de Petróleo da Grande Florianópolis ajuizou ação contra um posto de combustíveis pleiteando o desconto de um dia de trabalho de todos os empregados do posto. A ação foi julgada procedente e foi determinado o desconto. O fundamento da decisão é que uma lei ordinária, como é o caso da Lei n. 13.467, não poderia ter alterado o instituto da contribuição sindical, que é um tributo.

A decisão do Supremo Tribunal Federal põe um fim a discussão sobre a constitucionalidade do fim da contribuição obrigatória. No entanto, uma nova questão surge em relação às ações que tramitam nas Varas do trabalho e que determinaram o desconto da contribuição, tendo em vista a decisão da corte constitucional. Ou seja, a insegurança jurídica permanece.

Mas não apenas a contribuição sindical gera controvérsias. O Tribunal Superior do Trabalho (TST) publicou a Resolução Administrativa n. 1.953, constituindo uma Comissão formada por nove ministros, e com prazo de 60 dias, com a finalidade de regulamentar a aplicação da Lei 13.467 aos contratos de trabalho vigentes e processos em curso. As decisões nos mais diversos juízos e tribunais têm sido diversas: em alguns casos entende-se que a lei deva ser aplicada imediatamente aos processos em trâmite, noutras o entendimento é de que nas ações ajuizadas antes da entrada em vigor, a nova lei não se aplica.

Novamente a insegurança jurídica prevalece. Ainda que a aplicação da lei alcance os contratos de trabalho em vigor, no âmbito processual a regra não é a mesma. Esse foi o entendimento de uma juíza do trabalho em Santo Amaro, na Bahia. Para a magistrada, a decisão surpresa, com a aplicação da nova lei nos processos já em curso configuraria decisão surpresa e em manifesta violação aos princípios da segurança jurídica e devido processo legal. A mesma fundamentou a decisão no artigo 14 do Código de Processo Civil, segundo o qual a norma processual não retroagirá e será imediatamente aplicada nos processos em curso, respeitados os atos processuais praticados e as situações jurídicas consolidadas. A magistrada defendeu que é imprescindível que a parte tenha ciência das consequências jurídicas do ajuizamento ou defesa apresentados. Assim, não seria razoável o empregado que já havia ajuizado uma ação antes da entrada em vigor da lei e ser surpreendido com os honorários de sucumbência.

Todavia, esse entendimento não é compartilhado por todos os juízes. Decisões aplicando a nova lei aos processos em curso já tem sido proferidas. Em uma delas, um exempregado foi condenado ao pagamento de honorários de sucumbência no valor de R\$ 
750.000,00. Na ação, ajuizada em 2016 na Justiça do Trabalho de Rondonópolis, no Mato Grosso, foi atribuído o valor de 15 milhões à causa. A sentença foi parcialmente procedente e a empresa reclamada foi condenada ao pagamento de $\mathrm{R} \$ 10.000,00$. No restante dos pedidos a empresa foi isentada e o ex-empregado foi condenado ao pagamento de honorários de sucumbência no valor de $5 \%$ do valor da causa. Dentre os fundamentos da sentença, a magistrada afirmou que entre a publicação da lei e a sua entrada em vigor houve tempo suficiente para que as partes reavaliassem os riscos do processo.

Em situação semelhante, na $2^{\mathrm{a}}$ Vara do Trabalho de Volta Redonda, no Rio de Janeiro, uma ex-empregada foi condenada ao pagamento de honorários advocatícios no valor de $\mathrm{R} \$ 67.500,00$. A ação havia sido ajuizada antes da entrada em vigor da reforma trabalhista. Na sentença, o fundamento é de que os honorários seguem a regra do direito processual, e por essa razão, devem ser aplicados imediatamente, ainda que a ação tenha sido ajuizada antes da entrada em vigência da nova lei.

No entanto, entre os juízes esse entendimento não é pacífico. Para alguns, os honorários advocatícios são de natureza híbrida e não se configuram apenas como uma questão de ordem processual, tendo em vista que geram reflexos no direito da parte e do seu procurador. Com isso, inúmeros processos que estão tramitando e que aguardam sentença poderão ser julgados com a aplicação ou não da nova lei. Partes e procuradores envolvidos não tem segurança alguma quanto ao que irá ocorrer, gerando a insegurança.

Ainda, para complementar o quadro de insegurança jurídica, a $83^{\mathrm{a}}$ Vara do Trabalho de São Paulo extinguiu, com base na nova lei, 73 ações que foram ajuizadas na semana que antecedeu a sua entrada em vigor. O fundamento é de que, a partir da Lei n. 13.467 há necessidade de indicação do valor da causa, com a liquidação dos pedidos, sob pena de extinção do processo sem resolução do mérito, conforme previsão do $\S 3^{\circ}$ do artigo 840 da CLT. Para a magistrada que extinguiu as ações, o processo começa na tramitação e não na distribuição, o que também não é entendimento unânime entre magistrados do trabalho.

Assim, verifica-se que nas situações apresentadas a título exemplificativo, as decisões foram diversas, bem como os fundamentos que sustentaram as mesmas. Se um dos princípios fundamentais do Estado de Direito é a segurança jurídica, a Lei n. 13.467 tem trazido o efeito contrário, pois tem provocado uma avalanche de decisões, com diferentes fundamentos, para situações semelhantes.

Todavia, não é somente a segurança jurídica que se encontra ameaçada. Ao modificar radicalmente alguns institutos do Direito do Trabalho ou suprimir alguns dos 
direitos assegurados, inclusive pela Constituição Federal, a nova lei pode contribuir para a precarização das relações de trabalho.

\title{
2 A precarização do trabalho como reflexo da Lei n. 13.467
}

Ao modificar uma parte substancial da Consolidação das Leis do Trabalho, a Lei n. 13.467 provocou questionamentos e gerou dúvidas acerca da sua aplicabilidade. A Medida Provisória n. 808 determinou a aplicação da lei em todos os contratos de trabalho, inclusive naqueles firmados antes da sua entrada em vigor.

Entretanto, ainda que pacificado esse entendimento, permanecem dúvidas quanto aos seus efeitos. Cassar (2018, p. 14) assevera que a reforma trabalhista "é a resposta à crise e aos interesses dos empresários, pois altera mais de cem pontos da legislação trabalhista que, em sua maioria, prejudicam o trabalhador". Com isso, apesar de gerar mais empregos formais, a nova legislação pode contribuir para a precarização do trabalho.

\section{Nesse sentido, é importante destacar que}

\begin{abstract}
quando se fala em direito, que fora especificamente criado, com o objetivo de inibir as injustiças provocadas pela desigualdade negocial entre trabalhadores e empresários, como ocorreu com o Direito do Trabalho, a própria sobrevivência deste direito como ramo jurídico autônomo está condicionada à preservação de seu princípio básico, qual seja a preocupação com a Justiça Social. Um direito do trabalho, que na aplicação concreta, produza resultados injustos, perde, plenamente o seu sentido (SOUTO MAIOR, 2011, p. 558).
\end{abstract}

A reforma trabalhista teve como justificativa a promoção do emprego e o aumento dos níveis de competitividade no mercado internacional. Para tanto, fez-se necessário promover a flexibilização de normas trabalhistas, com a consequente redução de direitos dos trabalhadores. Todavia, o resultado pode ser o desequilíbrio nas relações laborais, retornandose aos patamares que marcaram a ascensão do capitalismo.

O triunfo global do capitalismo é o tema mais importante da história nas décadas que sucederam 1848. Foi o triunfo de uma sociedade que acreditou que o crescimento econômico repousava na competição da livre iniciativa privada, no sucesso de comprar tudo no mercado mais barato (inclusive trabalho) e vender no mais caro. Uma economia assim baseada, e portanto repousando naturalmente nas sólidas fundações de uma burguesia composta daqueles cuja energia, mérito e inteligência elevou-os a tal posição, deveria - assim se acreditava - não somente criar um mundo de plena distribuição material, mas também de crescente felicidade, oportunidade humana e razão, de avanço das ciências e das artes, numa palavra, um mundo de contínuo e acelerado progresso material e moral (HOBSBAWN, 1979, p. 17). 
Com base no argumento de incremento no crescimento econômico é que se justificava a relativização dos direitos trabalhistas. Todavia, a não intervenção estatal e a livre iniciativa privada contribuíram sobremaneira para acentuar a desigualdade: de um lado, viu-se o enriquecimento de uma classe e de outro lado, o agravamento da pobreza de boa parcela da população. Portanto, a relativização dos direitos não é o caminho para o desenvolvimento, porque se o crescimento econômico não vier acompanhado do desenvolvimento social, não é suficiente para assegurar a efetividade dos direitos fundamentais.

Um dos impactos da reforma trabalhista é a inversão da lógica principiológica que sustenta o Direito do Trabalho. O princípio da proteção, que é o princípio basilar, tem como objetivo promover o equilíbrio da relação desigual que se dá entre empregado e empregador. A hipossuficiência econômica em relação ao empregador faz com que o empregado tenha uma proteção maior, a partir de uma forte intervenção estatal. Porém, esse princípio também foi afetado pela nova lei. Exemplo disso é o artigo 611-A que autoriza a preponderância da convenção e do acordo coletivo de trabalho sobre a lei quando reduzir ou suprimir direitos, o que pode representar um retrocesso de conquistas e direitos arduamente conquistados ao longo dos anos (CASSAR, 2018).

Já no $\S 1^{\circ}$ do artigo $8^{\circ}$ da CLT tem-se uma modificação significativa e que põe em risco as garantias dos trabalhadores: o mesmo dispõe que o direito comum será fonte subsidiária do direito do trabalho. Entende-se por direito comum o direito civil, que possui uma principiologia própria. Apesar da autonomia do Direito do Trabalho, e dos princípios próprios que o regem, o direito comum poderá passar a utilizar-se do direito comum, no qual há, normalmente, uma paridade entre os contratantes e uma igualdade econômica e jurídica entre as partes (CASSAR, 2018), diferentemente do que ocorre no âmbito laboral, onde as partes não estão em condições de igualdade.

Veja-se a situação do trabalhador autônomo. A redação do artigo 442-B da CLT regula a contratação do autônomo, dispondo expressamente que, cumpridas por este as formalidades legais, ainda que a prestação seja contínua, não se configura vínculo empregatício. O objetivo é de assegurar maior segurança aos verdadeiros contratos de prestação de serviços autônomos (CASSAR, 2018). No entanto, é preciso cautela para que não ocorra justamente o contrário.

A pactuação de um contrato de prestação de serviço por um autônomo pode, de fato, mascarar a prestação subordinada de serviços, o que caracteriza a relação de emprego. Contudo, é preciso deixar claro que não se trata de tornar lícita a pejotização, que é uma 
fraude à legislação trabalhista e decorre da imposição do empregador para que o empregado constitua uma pessoa jurídica para prestar serviços que são objeto do contrato de trabalho.

A pejotização tem como objetivo central a redução dos custos por parte do empregador e com a transferência dos riscos da atividade econômica para o empregado:

\begin{abstract}
A pejotização, como o próprio nome define, refere-se ao processo de mascaramento e eliminação legal de relações de emprego, consolidando-se pela transformação do empregado em um prestador de serviços legalizado como pessoa jurídica. Trata-se, portanto, de eliminar o vínculo empregatício para reconhecer e estabelecer relações de trabalho com o agora trabalhador autônomo, então desprovido de direitos, proteções e garantias associados ao assalariamento. A pejotização está assentada na eliminação de custos de contratação como assalariado ao empregador, associada à transferência de riscos para o trabalhador. Ao transformar o trabalhador em pessoa jurídica, a empresa não paga os encargos sociais e os direitos vinculados à remuneração da contraprestação do serviço realizado, não segue a regulamentação da jornada e outros limites estabelecidos pela lei na utilização da força de trabalho. É uma forma de dispor de mão-de-obra de maneira muito mais barata e sem responsabilidades vinculadas ao assalariamento. (KREIN, 2017, p. 16)
\end{abstract}

Além do autônomo, outros contratos foram inseridos pela reforma trabalhista, destacando-se o contrato de trabalho intermitente e o teletrabalho. A inclusão de novas modalidades de contratos de trabalho, por si só, não significa avanços e ganhos para o trabalhador. De acordo com Krein (2017), é a dinâmica da economia que determina a geração de emprego e não a possibilidade de novas formas de contratação, como comprova a prevalência dos contratos de trabalho por prazo determinado. Em 2016, $96 \%$ do total de trabalhadores assalariados formais, conforme informações constantes na RAIS, eram por prazo indeterminado ou estatutário.

Nesse sentido,

A introdução de novas modalidades de contratação ou ampliação da utilização das já existentes não pode ser atribuída a eventual rigidez do mercado de trabalho, mas fundamentalmente como possibilidade de oferecer aos empregadores formas mais baratas de contratar a força de trabalho. A tendência, com isso, é agravar ainda a situação de um mercado de trabalho pouco estruturado, como é o brasileiro (KREIN, 2017, p. 02).

A pretensão da reforma trabalhista, de gerar mais empregos, ainda não se confirmou. Isso porque é preciso considerar que a simples geração de empregos formais não é suficiente para atender aos preceitos do direito do trabalho, tampouco do trabalho digno e decente ou dos valores sociais do trabalho.

Outra modalidade instituída pela reforma trabalhista está prevista no artigo no artigo 443 da CLT, é o trabalho intermitente. Pinheiro (2017, p. 187) defende que tal "modalidade pode vir a transformar a relação de emprego no país, na medida em que amplia o seu conceito, 
flexibilizando o requisito do trabalho não eventual e rompendo com o exercício disciplinar e diretivo do empregador".

De acordo com Barbosa (2018), a limitação máxima da jornada de trabalho está associada à saúde e segurança do trabalhador. A limitação da jornada tem em vista evitar a superexploração e as jornadas exaustivas. Contudo, não há, no ordenamento jurídico limitação acerca da jornada mínima.

Assim, pode-se dizer que no contrato de trabalho intermitente não há nenhuma prefixação de jornada a ser cumprida pelo empregado, sendo que o empregador irá acioná-lo quando houver a necessidade dos seus serviços. A alternância entre os períodos de prestação de serviços e de inatividade poderá fazer com que o empregado fique inativo por horas, dias ou meses (BARBOSA, 2018).

Apesar da justificativa de inclusão dessa modalidade ser a de retirada de inúmeros trabalhadores da informalidade, Pinheiro (2017) alerta para o risco de substituição de trabalhadores contratados por prazo indeterminado por contratos intermitentes. Ademais, afirma que essa forma de contratação contraria frontalmente uma das principais características do contrato de trabalho que é o fato dele ser comutativo. No contrato de trabalho intermitente, tem-se o contrato aleatório, o que é uma desnaturação do contrato de trabalho.

Há uma convergência na literatura especializada apontando para os riscos desse tipo de contratação. $\mathrm{O}$ empregado não sabe quando irá trabalhar, também não sabe quanto irá receber ao final do mês, ou até mesmo se irá receber alguma coisa, haja vista que poderá não ser chamado para trabalhar. Todavia, permanecerá à disposição do empregador, porém não será remunerado. Com isso, fica impossível para o trabalhador organizar a sua vida, tanto social quanto financeira, porque a remuneração dependerá do número de horas/dias trabalhados. Resta caracterizado, portanto, a transferência do risco do negócio para o empregado, pois ele somente será demandado quando o negócio assim o exigir (BARBOSA, 2018, p. 240-241).

Nesse sentido, o trabalho intermitente mostra-se extremamente prejudicial ao trabalhador:

O contrato intermitente significa transformar o trabalhador em just-in-time, pois legaliza a lógica da utilização da força de trabalho na exata medida das demandas do capital. Desta forma, ainda que tenha na determinação do valor hora de trabalho embutida a remuneração associada a direitos do trabalho, ele coloca o trabalhador em uma condição de alta instabilidade, incerteza e insegurança sobre sua própria reprodução social (KREIN, 2017, p. 03). 
A mesma preocupação é compartilhada por Garcia (2018), pois entende que ocorrerá a transferência ao empregado, que é a parte mais vulnerável da relação empregatícia, dos riscos da atividade econômica e, em consequência, o favorecimento à parte mais forte, que é o empregador. Além das consequências econômicas, pois o trabalhador não poderá ser organizar já que não sabe quando será chamado para trabalhar, haverá outros prejuízos decorrentes da perda da qualidade de vida.

Para além dessas questões que afastam as características basilares dos contratos de trabalho, Cassar (2018) destaca outras dúvidas que decorrem do contrato de trabalho intermitente: se as férias serão de 30 dias ou de um mês; se as férias serão usufruídas sem o respectivo pagamento, pois a previsão é de quitação das férias proporcionais ao final de cada período de trabalho; se a empregada que engravidar no período de inatividade terá direito a garantia provisória de emprego; se para contratação de aprendizes os empregados inativos entram na contagem, o mesmo ocorrendo para a instituição da Comissão Interna de Prevenção de Acidentes (CIPA).

Situação semelhante ocorre com o teletrabalho, que é realizado em local diverso do estabelecimento do empregador. Para tanto, são utilizados de recursos tecnológicos, de informática e de comunicação eletrônica. Entretanto, apesar de trabalhar fora do estabelecimento, a legislação não enquadrou como trabalhador externo, tanto é que incluiu o inciso III no artigo 62 da CLT para dispor que não se aplica o controle de jornada no teletrabalho.

Sanfelici e Fleischmann (2018) alertam que apesar das características sedutoras, tais como a ausência física do empregado nas dependências da empresa, a autorregulação de horário e a redução do tempo de deslocamento, o teletrabalho esconde um terrível fantasma que a é jornada exaustiva. Na verdade, segundo as autoras, criou-se "a figura do empregado sem limite de horário controlado à distância" (SANFELICI; FLEISCHMANN, 2018, p. 102). Ou seja, manteve-se o controle, talvez ainda maior do que quando o trabalho é desenvolvido de forma presencial, porém exime-se o pagamento das jornadas extraordinárias.

O controle do teletrabalhador é mais acentuado, pois é facilmente monitorado por web câmera, intranet, GPS, número de atividades, telefone, dentre outras, todavia não há previsão de pagamento de horas extraordinárias, adicional noturno, intervalo intrajornada e entrejornada (CASSAR, 2018).

A limitação de jornada tem caráter protetivo da saúde dos trabalhadores. Não basta a exceção inserta no artigo 62 da CLT para que se garanta o respeito aos limites estabelecidos. 
Mesmo à distância e longe do ambiente físico da empresa, o trabalhador continua sendo controlado pelo empregador, justamente pela utilização de meios telemáticos. Nesse sentido, não há nenhuma justificativa para a dispensa de limitação. A inconstitucionalidade do dispositivo é evidente, pois a exceção ao artigo $7^{\circ}$, inciso XIII da Constituição Federal exige um motivo de força que permitisse tal distinção em relação aos demais trabalhadores (SANFELICI; FLEISCHMANN, 2018).

Em relação ao dever de instruir os empregados em situação de trabalho acerca da prevenção de acidentes de trabalho e doenças ocupacionais, o artigo 75-E da CLT dispõe que o empregador deverá fazê-lo de maneira expressa e ostensiva. O trabalhador deverá assinar o termo de responsabilidade, comprometendo-se a seguir as orientações do empregador. Isso pode significar que "se o empregado adquirir uma doença profissional (tenossinovite, por exemplo), o empregador estará isento de qualquer responsabilidade subjetiva” (CASSAR, 2018, p. 52).

Há ainda outras situações que configuram a precarização do trabalho. Especialmente no que diz respeito à jornada de trabalho, como a flexibilização, a possibilidade de redução do intervalo para repouso e alimentação, a supressão da jornada in itinere e o tempo à disposição.

A supressão do pagamento das horas in itinere, prevista no $\S 2^{\circ}$ do artigo 58 da CLT, repousa na justificativa de que o tempo de deslocamento não se configura em tempo à disposição do empregador. O tempo despendido pelo empregado, desde a sua residência até a efetiva ocupação do posto de trabalho, ou para seu retorno, caminhando ou por qualquer meio de transporte, inclusive o fornecido pelo empregador, não será computado na jornada. $\mathrm{O}$ legislador, porém, não tratou das questões especiais, como o local de difícil acesso ou em local não servido por transporte público regular. Com isso, permanece a possibilidade de pleitear, na justiça do trabalho, o pagamento das horas in itinere quando se configurar essas excepcionalidades (SOUZA JUNIOR, 2017).

A possibilidade de flexibilização e até mesmo de supressão de direitos, previstas no artigo 611-A da CLT, que permite a negociação coletiva e que dispõe que a convenção coletiva e o acordo coletivo de trabalho têm prevalência sobre a lei quando dispuserem sobre pacto quanto à jornada de trabalho, banco de horas anual, redução do intervalo intrajornada, remuneração por produtividade, troca de dia de feriado, enquadramento do grau de insalubridade, dentre outros, também se configura como risco de precarização do trabalho. Isso porque "a flexibilização da utilização do tempo de trabalho tende a provocar 
desorganização na vida social e pessoal do trabalhador. O tempo voltado à produção se sobrepõe ao tempo da reprodução social [...]" (KREIN, 2017, p. 04).

A flexibilização das normas trabalhistas é reflexo da flexibilização do mercado de trabalho e pode ser dividida em três categorias: necessária, apenas nos casos de necessidade de recuperação da saúde da empresa; para adaptação, quando é necessário alterar as regras legais e moldá-las à realidade; e abusiva, quando reduz ou suprime direitos em prol do aumento do lucro empresarial (CASSAR, 2018). Desse modo, apenas as duas primeiras seriam possíveis, sendo vedada toda e qualquer flexibilização que represente prejuízos ou riscos aos direitos dos trabalhadores.

Além dessas questões, outros dispositivos da Lei n. 13.467 configuram-se em ameaças aos direitos fundamentais sociais e permitem a precarização do trabalho, o que, em última instância, representa retrocesso.

\section{Conclusão}

As mudanças são inevitáveis. Nos mais diversos âmbitos as mudanças são decorrência da evolução e das transformações que a sociedade passa ao longo do tempo. Não poderia ser diferente com a legislação, tampouco com o direito do trabalho. Os avanços na tecnologia, a mudança nos processos produtivos, a qualificação dos trabalhadores e outras exigências fazem parte da realidade.

Entretanto, nem sempre as mudanças são aceitas ou assimiladas. Em regra, mudanças provocam insegurança e inquietações, pois impõem a necessidade de abandonar um determinado status e seguir em direção ao desconhecido e incerto.

Não foi diferente com a reforma trabalhista promovida pela Lei n. 13.467, promulgada em julho de 2017 e em vigência desde 11 de novembro de 2017. Dúvidas e incertezas marcaram esse processo. Todavia, além das incertezas e inseguranças, que marcam a entrada em vigor de uma nova legislação, a reforma trabalhista colocou em discussão questão que estão no âmago do Direito do Trabalho e que se constituem nos seus fundamentos.

Com a presente pesquisa pretendeu-se analisar os impactos decorrentes dessa mudança e em resposta ao problema de pesquisa proposto inicialmente, concluiu-se que a insegurança jurídica e a precarização do trabalho foram os impactos mais relevantes.

A insegurança jurídica decorre das inúmeras Ações Diretas de Inconstitucionalidade, ajuizadas no Supremo Tribunal Federal e que discutem a constitucionalidade de vários 
dispositivos da legislação. Até o momento, apenas o fim da contribuição sindical obrigatória foi analisado pela Corte.

Ao mesmo tempo, há um número significativo de ações tramitando na Justiça do Trabalho, questionando alguns dispositivos da nova legislação. Algumas decisões têm sido no sentido contrário ao que dispõe a nova redação da Consolidação das Leis do Trabalho, fundamentadas na violação de preceitos constitucionais. Tais situações caracterizam a insegurança jurídica e comprometem o Estado de Direito.

Por outro lado, a precarização do trabalho tem-se mostrado como outro impacto negativo da reforma trabalhista. As novas modalidades de contratação, como o contrato intermitente de trabalho; a contratação do autônomo que, ainda que preenchidos os requisitos para configuração do vínculo empregatício, não é considerado empregado; a flexibilização de normas pela via da convenção e do acordo coletivo de trabalho, são exemplos dos riscos de violação aos direitos assegurados aos trabalhadores.

\section{Referências}

BARBOSA, Fernanda Pereira. Trabalhos em jornada reduzida: trabalho em tempo parcial e trabalho intermitente. In: COSTA, Ângelo Fabiano Farias da; MONTEIRO, Ana Claudia R.B.; BELTRAMELLI NETO, Silvio (Coord.). Reforma trabalhista - na visão de Procuradores do Trabalho. Salvador: Editora JusPodivm, 2018, p. 235-250.

BARROSO, Luís Robert. Interpretação e aplicação da Constituição: fundamentos de uma dogmática constitucional transformadora. 6. ed. São Paulo: Saraiva, 2004.

BRASIL. Lei de Introdução às normas do Direito Brasileiro. 2010. Disponível em http://www.planalto.gov.br/ccivil_03/decreto-lei/Del4657.htm. Acesso em 21 mar 2018.

CASSAR, Vólia Bomfim; BORGES, Leonardo Dias. Comentários à Reforma Trabalhista. 2.ed. ver., atual. e ampl. Rio de Janeiro: Forense; São Paulo: MÉTODO, 2018.

CANOTILHO, José Joaquim Gomes. Direito Constitucional. 6. ed. Coimbra: Livraria Almedina, 1993.

Direito Constitucional e Teoria da Constituição. Coimbra: Almedina, 2002.

GARCIA, Gustavo Filipe Barbosa. Curso de Direito do Trabalho. 12.ed. Rio de Janeiro: Forense; São Paulo: MÉTODO, 2018.

HOBSBAWN, Eric J. A era do capital: 1848 - 1875. São Paulo: Paz e Terra, 1979.

KREIN, José Dari [et al.]. Relações de Trabalho. Subsídios para a discussão sobre a reforma trabalhista no Brasil. Campinas: CESIT/UNICAMP, outubro, 2017. Disponível em 
http://www.cesit.net.br/wp-content/uploads/2017/11/Texto-de-Discuss\%C3\%A3o-4Relac\%C3\%B5es-de-trabalho.pdf. Acesso em 22 mar 2018.

MENDES, Gilmar Ferreira. Comentários ao art. 5, XXXVI. In: CANOTILHO, J.J. [et al.]. Comentários à Constituição do Brasil. São Paulo: Saraiva/Almedina, 2013, p. 368-374.

PÉREZ LUÑO, Antonio Enrique. Seguridad jurídica y sistema cautelar, 1990. Disponível em https://rua.ua.es/dspace/bitstream/10045/10828/1/Doxa7_12.pdf. Acesso em 23 mar 2018

PINHEIRO, Iuri. Contrato de trabalho intermitente. In: PINHEIRO, Iuri; OLIVEIRA, Cinthia; MIZIARA, Raphael; GASPAR, Danilo (coord.). Reforma trabalhista: os novos direitos material e processual do trabalho. Porto Alegre: Verbo Jurídico, 2017, p. 185-205.

REALE, Miguel. Teoria tridimensional do direito. 5. ed. São Paulo: Saraiva, 1994.

SANFELICI, Patrícia de Mello; FLEISCHMANN, Rogério Uzun. Teletrabalho: liberdade ou escravidão? In: COSTA, Ângelo Fabiano Farias da; MONTEIRO, Ana Claudia R.B.; BELTRAMELLI NETO, Silvio (Coord.). Reforma trabalhista - na visão de Procuradores do Trabalho. Salvador: Editora JusPodivm, 2018, p. 99-110.

SANTOS, Anselmo Luis dos; GIMENEZ, Denis Maracci. Desenvolvimento, competitividade e reforma trabalhista. Subsídios para a discussão sobre a reforma trabalhista no Brasil.

Campinas: CESIT/UNISCAMP, outubro, 2017. Disponível em http://www.cesit.net.br/wpcontent/uploads/2017/11/Texto-de-discuss\%C3\%A3o-8-Desenvolvimento-competitividade-ereforma-trabalhista.pdf. Acesso em 22 mar 2018.

SARLET, Ingo Wolfgang. A eficácia do direito fundamental à segurança jurídica: dignidade da pessoa humana, direitos fundamentais e proibição de retrocesso social no direito constitucional brasileiro. In. Revista Eletrônica sobre a reforma do Estado. Número 21. Salvador, Março/Abril/Maio, 2010. Disponível em https://www.olibat.com.br/documentos/SARLET.pdf. Acesso em 23 mar 2018.

SOUTO MAIOR, Jorge Luiz. Curso de Direito do Trabalho - Teoria Geral do Direito do Trabalho - Volume I Parte I. São Paulo: LTR, 2011.

SOUZA JUNIOR [et al.]. Reforma trabalhista, tempo à disposição e jornada laboral. In: PINHEIRO, Iuri; OLIVEIRA, Cinthia; MIZIARA, Raphael; GASPAR, Danilo (coord.). Reforma trabalhista: os novos direitos material e processual do trabalho. Porto Alegre: Verbo Jurídico, 2017, p. 133-170. 